\title{
ASCARIDIOSE DES VOIES BILIAIRES CHEZ DEUX PORCELETS
}

\author{
Par V. ALLEAUX \\ Vétérinaire sanitaire
}

Les sujets atteints ont six semaines environ et font partie d'un lot de cinq porcelets expédiés vivants de l'ouest sur Paris. L'un d'eux a été trouvé mort à l'arrivée ; son cadavre en voie de putréfac-

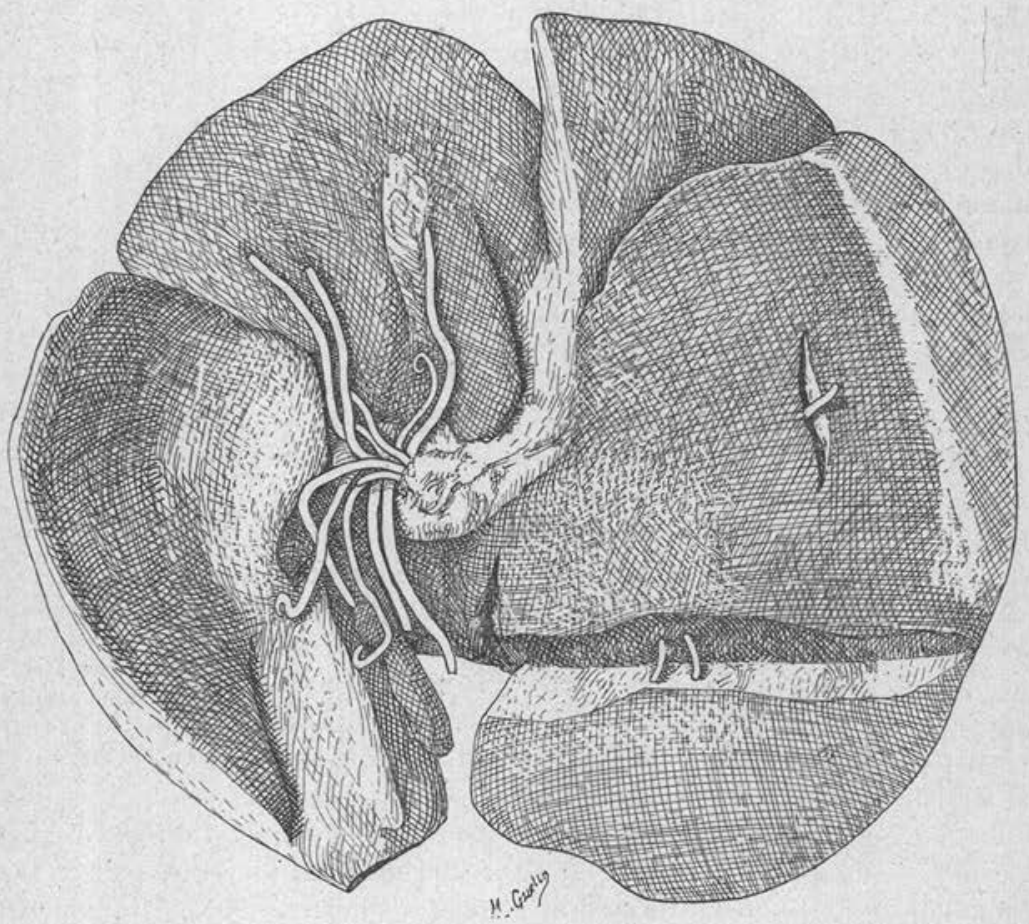

Fig. - Foie de porcelet envahi par des Ascaris.

tion n'a pas été autopsié. Deux autres refusent toute nourriture, demeurent étendus sur la litière et manifestent de vives douleurs ; leur ventre paraît très sensible. Bien que destinés à l'élevage, ils sont sacrifiés parce qu'on craint de les voir périr. Ils sont présentés à l'inspection le lendemain de l'abattage. Les carcasses sont en bon

Annales de Parasitologie, T. I, No 4 . - Octobre 1923. 
état de chair et de graisse pour l'âge des sujets, mais frappent immédiatement par une coloration jaune verdêtre très accusée des séreuses et du tissu conjonctif et adipeux. Des viscères, nous ne pou vons examiner que le poumon et le foie. Le poumon présente des foyers de strongylose. Le foie est jaune foncé ; du cholédoque (rupturé au ras du viscère par arrachement au moment de l'enlèvement de la masse intestinale) on voit faire saillie un faisceau d'ascarides. Les vers longs d'une dizaine de centimètres sont fortement enfoncés dans l'organe où ils sont retenus par leur masse qui obture complètement les voies biliaires. Plusieurs coupes du tissu hépatique montrent que l'invasion par les ascaris n'est pas limitée à l'origine du cholédoque. Comme on le voit sur la figure, des vers sont retrouvés, sur ces coupes, même au voisinage des bords de l'organe, dans des canaux qui sont complètement remplis par leur hôte. En aucun de ces points, on ne peut, macroscopiquement, déceler de lésions des parois des canaux parasités.

Le foie de l'autre porcelet présente exactement les mêmes caractères : paquet d'ascarides bouchant le cholédoque et nombreux ver's dans les canaux biliaires provoquant par rétention un ictère intense.

La vésicule biliaire ayant été enlevée de suite ainsi que le pancréas pendant l'habillage, nous n'avons pu voir si ces organes étaient également envahis. Les intestins étaient détruits et n'ont pu être examinés, mais, d'après la personne qui a préparé les animaux, le tube digestif contenait de nombreux parasites.

L'ascaridiose des voies biliaires est bien connue chez l'homme et a été signalée plusieurs fois chez le porcelet. Si elle semble rare dans cette espèce, c'est sans doute parce que l'autopsie des jeunes sujets n'est pas souvent pratiquée et qu'aux abattoirs ce sont des adultes qui sont sacrifiés et examinés. Cependant, en 1921, Cauchemez a signalé un cas d'oblitération du cholédoque par les ascarides sur un pore de six mois, saisi pour ictère aux abattoirs de Vaugirard.

Laboratoire des Halles centrales et Laboratoire de Parasilologie de la Facullé de médecine de Paris. 